МРТНИ 65.35.33

\author{
РАЗРАБОТКА СНЕКОВ ФУНКЦИОНАЛЬНОГО НАЗНАЧЕНИЯ \\ ${ }^{1}$ Ю.А. СИНЯВСКИЙ*, ${ }^{1}$ Д.Н. ТУЙГУНОВ, ${ }^{1}$ Е.А. ДЕРИПАСКИНА, ${ }^{2}$ Х.С. САРСЕМБАЕВ, \\ ${ }^{2}$ C.M. БАРМАК, ${ }^{2}$ B.A. РЕДЬКО \\ ${ }^{1}$ ТОО «ОО Казахская академия питания» Казахстан, г. Алматы, ул. Клочкова 66 \\ ${ }^{2}$ НИИ «Пищевой и перерабатывающей промышленности» Казахстан, \\ г. Алматы, пр. Гагарина, 238 Г. \\ Электронная почта автора-корреспондента: sinyavskiy@list.ru*
}

\begin{abstract}
В статье излагаются сведения по разработке новых функциональных снеков на основе местного традиционного и нетрадиционного сырья. Уникальность состава снеков связана с присутствием в рецептуре сухого кобыльего и верблюжьего молока, а также фруктовых и овощных пюре, сухих штаммов лакто- и бифидобактерий, фукоидана и других пищевых ингредиентов с повыщенной пищевой и биологической ценностью. Оценка химического состава пищевой и биологической ценности снеков свидетельствует об их направленных антиоксидантных, детоксицирующих и иммуностимулирующих свойствах. Снеки функционального назначения рекомендуются к использованию широким слоям населения, включая альпинистов, летчиков гражданской и военной авиации, спортсменов, а такэе лицам при чрезвычайных ситуациях и в экстремальных условиях, неблагоприятно влияющих на здоровье человека.
\end{abstract}

Ключевые слова: снеки, профилактика, плоды, овощи, сухое молоко.

\title{
DEVELOPMENT OF FUNCTIONAL PURPOSE SNACKS
}

\author{
${ }^{l} Y U . A . S I N Y A V S K Y^{*},{ }^{2} D . N . T U I G U N O V,{ }^{2}$ E.A. DERIPASKINA, ${ }^{3}$ H.S. SARSEMBAEV, \\ ${ }^{3}$ S.M. BARMAK, ${ }^{3}$ V.A. REDKO. \\ $\left({ }^{1}\right.$ «Almaty Technological University» JSC, Kazakhstan, 050012, city of Almaty, Tole bi str. 100 \\ ${ }^{2}$ «Kazakh Academy of Nutrition» LLP, Kazakhstan, city of Almaty, Klochkova str. 66 \\ 3 «Research Institute of Food and Processing Industry» Kazakhstan, city of Almaty, \\ Gagarin Ave., 238 G,) \\ Corresponding author e-mail: sinyavskiy@list.ru*
}

The article provides information on the development of new functional snacks based on local traditional and non-traditional raw materials. The uniqueness of the composition of snacks is associated with the presence in the recipe of dry mare's and camel's milk, as well as fruit and vegetable purees, dry strains of lacto and bifidobacteria, fucoidan and other food ingredients with increased nutritional and biological value. Evaluation of the chemical composition of the nutritional and biological value of snacks indicates their targeted antioxidant, detoxifying and immunostimulating properties. Functional snacks are recommended for use by the general public, including climbers, pilots of civil and military aviation, athletes, as well as in emergencies and conditions that adversely affect human health.

Keywords: snacks, prevention, fruits, vegetables, milk powder.

\section{ФУНКЦИОНАЛДЫ СНЕКТЕРДІ ДАМЫТУ ӘДІСТЕРІ}

\section{${ }^{1}$ Ю.А. СИНЯВСКИЙ*, ${ }^{2}$ Д.Н. ТУЙГУНОВ ${ }^{2}$ Е.А. ДЕРИПАСКИНА, ${ }^{3}$ Х.С. САРСЕМБАЕВ, ${ }^{3}$ C.M. БАРМАК, ${ }^{3}$ B.A. РЕДЬКО.}

\footnotetext{
( ${ }^{1}$ «Алматы технологиялық университеті», Қазақстан, Алматы қ., Толе би көш., 100

${ }^{2}$ «Қазақ тағамтану академиясы» ЖШС, Қазақстан, Алматы қ., Клочков көш., 66,

${ }^{3}$ «Қазақ қайта өңдеу және тағам өнеркәсіптері ғылыми-зерттеу институты», Қазақстан,

Алматы к., Гагарин даңғ., 238 Г,

Автор-корреспонденттің электрондық поштасы: sinyavskiy@ list.ru*
} 
Мақалада жергілікті дәстүрлі жене дәстүрлі емес иикізатқа негізделген жсаңа функционалдық тагамдарды жнасау туралы мәліметтер ұсынылады. Тавамдық снек құрамының бірегейлігі тавам құрамында құрzақ бие мен түйе сүтінің, сондай-ақ жееміс-көкөніс езбелерінің, лакто жюне бифидобактериялардың құрвақ штаммдарының, фукоиданның және тавамдық және биологиялық құндылывы жсовары басқа құрам бөліктердің болуымен байланысты. Снек тавамының тавамдық жсәне биологиялық құндылызының химиялық құрамын бавалау олардың мақсатты антиоксидантты, детоксикациялау жсәне иммуностимуляциялы қасиеттерін көрсетеді. Функционалдық пайдалануга арналzан снектік тазамдар жалпылама халық топтарына, оның ішінде альпинистерге, азаматтық жжән әскери авиация ұшқыштарына, спортшыларва, сондай-ақ төтенше жсавдайлар мен адам денсаулывына кері әсер ететін жсавдайларда қолданува ұсынылады.

\section{Негізгі сөздер: тағамдар, алдын алу, жемістер, көкөністер, құрғақ сүт.}

\section{введение}

На сегодняшний день достаточно быстро развивается производство снековой продукции, растет и развивается рынок, увеличиваются производственные мощнос-ти, растет желание потребителя использовать в питании больше закусок, перекусов [1].

В последние годы исследованию конъюнктуры рынка снековой продукции посвящается все больше публикаций в научных и периодических специализированных изданиях, что объясняется расширением рынка и повышением к нему научнопрактического интереса [2-3].

Рынок несладких, низкокалорийных снеков, является одним из перспективных сегментов рынка продуктов быстрого питания в Казахстане, демонстрирующего на протяжении последних лет высокие показатели роста.

К сожалению, следует отметить, что обильное употребление снековой продукции, в частности различных чипсов, сухариков, обогащенных различными синтетическими ароматизаторами и искусственными добавками, может негативно сказаться на здоровье, в первую очередь молодежи, активно увлекающейся употреблением снеков [4]. Кроме того, популярность «перекусов» способствует увеличению потребления калорий, что в сочетании с недостаточной физической нагрузкой оказывает негативный эффект на здоровье человека, в частности приводит к росту избыточной массы тела и ожирения [5].

Учитывая популярность снеков и стремление потребителей к правильному, здоровому питанию, изменения в структуре ассортимента снековой продукции должны быть направлены на создание снеков с повышенной пищевой и биологической ценностью [6].
Учитывая вышеизложенное, разработка нового поколения снеков на основе молочного, зернового и плодоовощного сырья, исключающего использование различного рода искусственных пищевых добавок, является инновационным направлением в пищевой промышленности, имеющим чрезвычайно важное практическое значение и социальную значимость [7].

Учитывая разнообразие фруктового, ягодного, овощного и зернового сырья в Республике Казахстан, перспективным является разработка комбинированных снеков функционального назначения.

Дополнительное обогащение снеков молоком различных сельскохозяйственных животных, а также комплексом витаминов, макро и микроэлементов в значительной степени повышает их пищевую и биологическую ценность и придает им направленные лечебно-профилактические свойства.

Учитывая вышеизложенное, целью настоящего исследования явилась разработка новой снековой продукции на фруктовой, овощной, зерновой и молочной основах с направленными профилактическими свойствами.

Материалы и методы исследования.

В качестве сырьевой основы нами были использованы яблоки, курага, изюм, инжир, дыня, миндаль, грецкий орех, арахис, семена тыквы, семена подсолнечника, кабачки, тыква сладкая, перец болгарский, сухое кобылье и верблюжье молоко.

В работе использовались физико-химические и технологические методы исследования. Массовую долю белка определяли методом Кьельдаля по ГОСТ 23327-98 [8]. Массовую долю жира определяли кислотным методом по ГОСТ 5867-90 [9].

Массовую концентрацию углеводов, а также содержание витаминов в новых видах снеков определяли методом высокоэффек- 
тивной жидкостной хроматографии (ВЭЖХ) [10-12]. Определение содержания минеральных веществ в батончиках проводили в соответствии с ГОСТ ISO 762-2013 [13]

\section{Результаты и их обсуждение.}

С учетом пищевой и биологической ценности используемого растительного и животного сырья нами были разработаны рецептуры на новые виды снековой продукции, которые представлены в таблицах 1-3.

Таблица 1- Рецептура на молочно-фруктовые батончики готовой продукции из расчета на 10 кг (Рецептура №1).

\begin{tabular}{|c|c|c|}
\hline $\begin{array}{c}\text { № } \\
\text { п/п }\end{array}$ & Наименование ингредиентов & $\begin{array}{c}\text { Количество, } \\
\text { кг }\end{array}$ \\
\hline 1 & Яблочное пюре & 1,0 \\
\hline 2 & Курага & 0,5 \\
\hline 3 & Персиковое пюре & 1,0 \\
\hline 4 & Пюре из черной смородины & 1,0 \\
\hline 5 & Клюква сушеная & 0,5 \\
\hline 6 & Изюм сушеный & 0,5 \\
\hline 7 & Инжир сушеный & 0,5 \\
\hline 8 & Дынное пюре & 1,0 \\
\hline 9 & Миндаль измельченный & 0,3 \\
\hline 10 & Грецкий орех измельченный & 0,3 \\
\hline 11 & Арахис измельченный & 0,3 \\
\hline 12 & Сухое кобылье молоко & 1,5 \\
\hline 13 & Активированный пористый & 1,6 \\
& овес измельченный & \\
\hline
\end{tabular}

Таблица 2- Рецептура на молочно-овощные батончики с добавлением активированного пористого овса из расчета на 10 кг (Рецептура №2).

\begin{tabular}{|c|c|c|}
\hline $\begin{array}{c}\text { № } \\
\text { п/п }\end{array}$ & Наименование ингредиентов & $\begin{array}{c}\text { Количество, } \\
\text { кг }\end{array}$ \\
\hline 1 & Яблочное пюре & 2,15 \\
\hline 2 & Пюре сладкой тыквы & 1,5 \\
\hline 3 & Облепиховое пюре & 0,5 \\
\hline 4 & Сухое верблюжье молоко & 1,5 \\
\hline 5 & Порошок мальтодекстрина & 1,5 \\
\hline 6 & $\begin{array}{c}\text { Порошок пектина } \\
\text { цитрусового }\end{array}$ & 0,2 \\
\hline 7 & $\begin{array}{c}\text { Активированный пористый } \\
\text { овес измельченный }\end{array}$ & 1,5 \\
\hline 8 & Миндаль измельченный & 0,3 \\
\hline 9 & Пюре перца болгарского & 0,5 \\
\hline 10 & $\begin{array}{c}\text { Витаминный премикс } \\
\text { (порошок) }\end{array}$ & 0,1 \\
\hline 11 & Сухие культуры лакто и \\
бифидобактерий & 0,1 \\
\hline 12 & Порошок ресвератрола & 0,05 \\
\hline 13 & Порошок лимонной кислоты & 0,05 \\
\hline 14 & Порошок фукоидана & 0,05 \\
\hline \multicolumn{3}{|c|}{} \\
\hline
\end{tabular}


Таблица 3- Рецептура на молочно-фруктовые батончики с добавлением активированной пористой гречки из расчета на 10 кг (Рецептура №3).

\begin{tabular}{|c|c|c|}
\hline $\begin{array}{c}\text { № } \\
\text { п/п }\end{array}$ & Наименование ингредиентов & $\begin{array}{c}\text { Количество, } \\
\text { кг }\end{array}$ \\
\hline 1 & Активированная пористая гречка & 1,0 \\
\hline 2 & измельченная & 0,4 \\
\hline 3 & Сародыши пшеницы измельченные & 1,0 \\
\hline 4 & Сухое верблюжье молоко & 1,5 \\
\hline 5 & Порошок мальтодекстрина & 1,5 \\
\hline 6 & Сухое кобылье молоко & 1,0 \\
\hline 7 & Активированный пористый овес & 1,0 \\
\hline 8 & измельченный & 0,3 \\
\hline 9 & Миндаль измельченный & 1,0 \\
\hline 10 & Пюре персиковое & 0,1 \\
\hline 11 & Сухие культуры лакто и бифидобактерий & 0,1 \\
\hline 12 & Финики сушеные & 1,0 \\
\hline 13 & Порошок лимонной кислоты & 0,05 \\
\hline 14 & Порошок фукоидана & 0,05 \\
\hline
\end{tabular}

Органолептические показатели снеков представлены в таблице 4.

Таблица- 4. Органолептические показатели снеков.

\begin{tabular}{|c|c|}
\hline $\begin{array}{c}\text { Наименование } \\
\text { показателя }\end{array}$ & Характеристики батончиков \\
\hline $\begin{array}{c}\text { Внешний вид, } \\
\text { форма }\end{array}$ & $\begin{array}{c}\text { Прямоугольная или овальная с ровной поверхностью, } \\
\text { равномерная по толщине, целая, без обломанных граней, } \\
\text { сохраняющие свою форму при укладке в тару и транспортировке }\end{array}$ \\
\hline Цвет & $\begin{array}{c}\text { Свойственный цвету используемого сырья, входящих в состав } \\
\text { батончиков, допускается более темные ил светлые оттенки }\end{array}$ \\
\hline Вкус и запах & $\begin{array}{c}\text { Свойственные используемому сырью и добавкам, входящих в } \\
\text { состав батончиков. Посторонний вкус и запах не допускаются }\end{array}$ \\
\hline Консистенция & $\begin{array}{c}\text { Плотная с включением измельченных частиц овощей, фруктов, } \\
\text { орехов и зерновых добавок. Допускается незначительная } \\
\text { крошливость. }\end{array}$ \\
\hline
\end{tabular}

По физико-химическим показателям снеки соответствуют следующим значениям: массовая доля влаги не более $20 \%$, массовая доля пищевых волокон не менее 1\%. Посторонние примеси не допускаются.

Созданные снеки отличаются уникальным составом, содержащим богатый белковый, жировой, углеводный, витаминный и минеральный комплексы, что подтверждено по данным исследований, представленных в таблице 5 .

Как видно из представленных данных обогащение снеков сухим кобыльим и верблюжьим молоком как в комбинации, так и раздельно, наряду с фруктовыми и овощными пюре (персиковое , яблочное, тыквенное, облепиховой, пюре перца болгарского), миндалем, финиками, клюквой, инжиром, изюмом, курагой), богатыми витаминами- антиоксидантами, аскорбиновой кислотой, витаминами группы В, железом, цинком, магнием, а также моно- и дисахаридами, пищевыми волокнами, растительными белками и жирами, включая полиненасыщенные жирные кислоты, в значительной степени способствует не только повышению их пищевой и биологической ценности, но придает снекам направленные профилактические характеристики, что обосновывает целесообразность использования данных продуктов самостоятельно или в комплексной терапии целого ряда заболеваний, включая железодефицитную анемию, избыточную массу тела, а также для повышения защитных механизмов и повышения адаптационных возможностей организма при действии неблагоприятных факторов окружающей среды. 
Таблица 5- Химический состав новых снеков функционального назначения из расчета на 100 г продукта.

\begin{tabular}{|c|c|c|c|c|}
\hline $\begin{array}{c}\text { Наименование } \\
\text { рецептур }\end{array}$ & Белки, г & Жиры, г & $\begin{array}{c}\text { Углеводы, } \\
\text { г }\end{array}$ & $\begin{array}{c}\text { Калорийность, } \\
\text { ккал/кДж }\end{array}$ \\
\hline Рецептура №1 & $6,96 \pm 0,71$ & $7,24 \pm 0,66$ & $27,26 \pm 1,30$ & $202,03 / 845,29$ \\
\hline Рецептура №2 & $6,12 \pm 0,32$ & $8,52 \pm 0,96$ & $26,74 \pm 0,34$ & $208,12 / 870,77$ \\
\hline Pецептура №3 & $10,66 \pm 0,90$ & $13,68 \pm 1,00$ & $46,56 \pm 3,25$ & $352,02 / 1472,85$ \\
\hline
\end{tabular}

Наряду с белками, жирами и углеводами, разработанные снеки содержат водо- и жирорастворимые витамины, микроэлементы, а также пищевые волокна. Витаминный состав батончиков представлен в таблице 6.

Таблица 6. Содержание витаминов в снеках функционального назначения в мг на 100г продукта.

\begin{tabular}{|l|c|c|c|c|}
\hline \multirow{2}{*}{$\begin{array}{l}\text { Рецептуры } \\
\text { снеков }\end{array}$} & \multicolumn{4}{|c|}{ Наименование витаминов } \\
\cline { 2 - 5 } & $\mathrm{C}$ & $\mathrm{A}$ & $\mathrm{PP}$ & $\mathrm{B}_{1}$ \\
\hline Рецептура №1 & $37,42 \pm 2,63$ & $0,003 \pm 0,01$ & $1,22 \pm 0,3$ & $0,15 \pm 0,02$ \\
\hline Рецептура №2 & $33,34 \pm 2,52$ & $0,05 \pm 0,01$ & $0,51 \pm 0,05$ & $0,20 \pm 0,0,2$ \\
\hline Рецептура №3 & $19,46 \pm 0,52$ & $4,86 \pm 0,41$ & $1,26 \pm 0,20$ & $0,24 \pm 0,02$ \\
\hline
\end{tabular}

Уровень микроэлементов, в частности, железа в 1-3 рецептурах снеков составлял 12,4 ; 15,0 и 2,3 мг, содержание кальция варьировало от 68,4 до 286,4мг, а количество магния лежало в пределах от 33,2 до 71,6 мг из расчёта на 100 г продукта соответственно. Содержание кальция существенно зависело от присутствия в снеках сухого кобыльего и верблюжьего молока. Включение в состав рецептуры снеков сухих культур лакто и бифидобактерий с высоким титром полезных микроорганизмов является благоприятным фактором для работы желудочно-кишечного тракта, усиления защитных механизмов организма, а также для снижения риска токсических отравлений. Детоксицирующие свойства снеков связаны с присутствием в рецептурах пектина и пищевых волокон, содержащихся в овощном и фруктовом сырье.

Включение в состав снеков фукоидана полисахарида из бурых водорослей северных морей, направлено на повышение иммунитета, регуляцию опорно-двигательной системы, а также для повышения антиоксидантных возможностей организма. Особый интерес представляет включение в состав снеков активированного пористого овса и активированной пористой гречки, приготовленных по специальной экструзионной технологии, позволяющих максимально сохранить в них основные биологически активные вещества, включая макро-и микроэлементы, витамины, полисахариды, пищевые волокна, благоприятно влияющие на работу желудочнокишечного тракта, усиливающих перисталь- тику кишечника, снижающих риск токсических отправлений и способствующих профилактики обменно-алиментарных нарушений, в том числе сахарного диабета второго типа.

\section{Заключение, выводы}

Таким образом, созданные новые рецептуры снековой продукции, выполненные в виде фруктово-молочных, молочноовощных с добавлением активированного пористого овса и молочно-фруктовых с добавлением активированной пористой гречки батончиков, отличаются повышенной пищевой и биологической ценностью, а также направленными профилактическими свойствами.

Следует отметить новизну предлагаемых снеков, в комбинации с сухим кобыльим и верблюжьим молоком, имеющих высокую биологическую ценность и придающих продуктам определенную профилактическую направленность в части повышения защитных, антиоксидантных и детоксицирующих возможностей организма.

Разработанные снеки могут быть успешно использованы спортсменами, альпинистами, лётчиками военной и гражданской авиации, альпинистами, космонавтами, а также при чрезвычайных ситуациях различными половозрастными категориями населения.

СПИСОК ИСПОЛЬЗОВАННОЙ ЛИТЕРАТУРЫ 1. Новицкая Л.Ю., Орловская М.А. Перспективы развития рынка снеков в России 
//Ученые труды Российской академии адвокатуры и нотариата, 2019. - №4(55). - С. 39-43.

2. Сохацкая А.В. Исследование условий повышения конкурентоспособности снековой продукции предприятий пищевой отрасли //Технологический аудит и резервы производства, - 2016. - №6/4(32). - С. 35-41.

3. Голубева О.В., Белоусова К.В., Булганина C.В., Большакова Ю.С. Маркетинговое исследование спроса на снековую продукцию потребителями // Инновационная экономика: перспективы развития и совершенствования, - 2019. - №2(36). - С. 195-201.

4. Коробейникова Ю. Снеки: вчера, сегодня, завтра // Статья в сборнике трудов конференции: Практико-ориентированные молодежные исследования проблем региона. - Тюмень, 2014. С. 95-97.

5. Coumans J.M Emotion-driven impulsiveness and snack food consumption of European adolescents: Results from the I. Family study / Coumans J.M., Danner U.N., Decker A. //Appetite, 2018. - V.123. № 1. - P. 152-159.

6. Bellisle F. Meals and snacking, diet quality and energy balance // Physiology \& Behavior, 2014. - V. 134. - P. 38-43.

7. Нилова Л. П., Малютенкова С. М. Продовольственная корзина для здорового питания в условиях мегаполиса // Международный научный журнал, 2017. - № 4. - С. 31-35.

8. ГОСТ 23327-98 «Молоко и молочные продукты. Метод измерения массовой доли общего азота по Кьельдалю и определение массовой доли белка». - Введ. 2002-01-01. М.: Стандартинформ, 2009. - 12c.

9. ГОСТ 5867-90 «Молоко и молочные продукты. Методы определения жира». - Введ. 1991-07-01. М.: Стандартинформ, 2009. - 16с.

10. ГОСТ Р 54760-2011 «Продукты молочные составные и продукты детского питания на молочной основе. Определения массовой концентрации моно- и дисахаридов методом высокоэффективной жидкостной хроматографии». - Введ. 2013-01-01. М.: Стандартинформ, 2012. - 12c.

11. ГОСТ 32903-2014. «Определение водорастворимых витаминов: тиамина (B1), рибофлавина (В2), пиридоксина (В6) и никотинамида (РР) методом обращенно-фазовой высокоэффективной жидкостной хроматографии». - Введ. 2016-01-01. - М.: Стандартинформ, 2014. - 28c.

12. ГОСТ Р ЕН 14130-2010 «Продукты пищевые. Определение витамина С с помощью высокоэффективной жидкостной хроматографии». - Введ. 2012-01-01. - М.: Стандартинформ, 2012. -15 c.
13. ГОСТ ISO 762-2013 «Продукты переработки фруктов и овощей. Определение содержания минеральных примесей». - Введ. 2015-07-01. - М.: Стандартинформ, 2014. - 7c.

\section{REFERENCES}

1. Novickaja L.Ju., Orlovskaja M.A. Perspektivy razvitija rynka snekov v Rossii // Uchenye trudy Rossijskoj akademii advokatury i notariata, 2019. - №4(55). - S. 39-43. ( in Russian)

2. Sohackaja A.V. Issledovanie uslovij povyshenija konkurentosposobnosti snekovoj produkcii predprijatij pishhevoj otrasli // Tehnologicheskij audit i rezervy proizvodstva, 2016. - №6/4(32). - S. 35-41.( in Russian)

3. Golubeva O.V., Belousova K.V., Bulganina S.V., Bol'shakova Ju.S. Marketingovoe issledovanie sprosa na snekovuju produkciju potrebiteljami // Innovacionnaja jekonomika: perspektivy razvitija i sovershenstvovanija, - 2019. - №2(36). - S. 195-201. ( in Russian)

4. Korobejnikova Ju. Sneki: vchera, segodnja, zavtra // Stat'ja v sbornike trudov konferencii: Praktiko-orientirovannye molodezhnye issledovanija problem regiona. - Tjumen', 2014. - S. 95-97.

5. Coumans J.M Emotion-driven impulsiveness and snack food consumption of European adolescents: Results from the I. Family study / Coumans J.M., Danner U.N., Decker A. // Appetite, 2018. - V.123. № 1. - P. 152-159.

6. Bellisle F. Meals and snacking, diet quality and energy balance // Physiology \& Behavior, 2014. - V. 134. - P. 38-43.

7. Nilova L. P., Maljutenkova S. M. Prodovol'stvennaja korzina dlja zdorovogo pitanija $\mathrm{v}$ uslovijah megapolisa // Mezhdunarodnyj nauchnyj zhurnal, 2017. - № 4. - S. 31-35. ( in Russian)

8. GOST 23327-98 «Moloko i molochnye produkty. Metod izmerenija massovoj doli obshhego azota po K'el'dalju i opredelenie massovoj doli belka». - Vved. 2002-01-01. M.: Standartinform, 2009. - 12s.

9. GOST 5867-90 «Moloko i molochnye produkty. Metody opredelenija zhira». - Vved. 199107-01. M.: Standartinform, 2009. - 16s.

10. GOST R 54760-2011 «Produkty molochnye sostavnye $\mathrm{i}$ produkty detskogo pitanija na molochnoj osnove. Opredelenija massovoj koncentracii mono- i disaharidov metodom vysokojeffektivnoj zhidkostnoj hromatografii». - Vved. 2013-01-01. M.: Standartinform, 2012. - 12s. 